06

\title{
Влияние содержания технического углерода на фазовый состав и электропроводность полимерного композита
}

\author{
(c) А.М. Зюзин, А.А. Карпеев, Н.В. Янцен, В.В. Наумкин \\ Национальный исследовательский Мордовский государственный университет им. Н.П. Огарева, Саранск, Россия \\ E-mail: zyuzin.am@rambler.ru
}

Поступило в Редакцию 28 июля 2020г.

В окончательной редакции 14 сентября 2020 г.

Принято к публикации 14 сентября 2020 г.

\begin{abstract}
Исследовано влияние технического углерода на фазовый состав в композиционном материале на основе этиленвинилацетата. Обнаружено существование дополнительной (более высокотемпературной) полимерной кристаллической фазы, относительная доля которой прямо связана с содержанием технического углерода. Показано, что насыщение пероксидом существенно влияет на полиморфизм композита и его электропроводность.
\end{abstract}

Ключевые слова: полимерные композиты, фазовый состав, электропроводность, технический углерод.

DOI: 10.21883/PJTF.2020.24.50424.18486

Композиционные электропроводящие материалы на основе полимеров находят все более широкое применение в производстве саморегулирующихся нагревательных элементов, экранных оболочек высоковольтных кабелей, различного типа электродов, оболочек электромагнитного экранирования и ряда других [1-4]. Поэтому композиты с техническим углеродом (ТУ) привлекают большое внимание исследователей и разработчиков новых материалов [5-10]. Несмотря на большое число работ, посвященных исследованиям композитов, особенности фазового состава и его температурной трансформации в композитах с ТУ на основе этиленвинилацетата остаются недостаточно изученными. Важным представляется и исследование влияния насыщения пероксидом, используемым для сшивки матрицы, на фазовый состав и другие характеристики композитов.

В настоящей работе исследовано влияние содержания ТУ и насыщения пероксидом композитного материала на основе матрицы из этиленвинилацетата на его фазовый состав и электропроводность. В качестве наполнителя, обеспечивающего электропроводность, использовался технический углерод С40 серии „ОМСАRВ“, содержание которого варьировалось от 5 до 35 wt.\%. Образцы композита были получены путем смешивания в расплаве полимерной матрицы на лабораторном экструдере ЕХ30. Затем часть образцов выдерживалась в течение $30 \mathrm{~min}$ в расплаве пероксида при температуре $55^{\circ} \mathrm{C}$. Толщина образцов, которые изготавливались путем прессования, составляла $2 \mathrm{~mm}$. Исследования проводились методом дифференциальной сканирующей калориметрии (ДСК) на установке METTLER TOLEDO DSC823e в диапазоне температур $20-150^{\circ} \mathrm{C}$, рентгеноструктурный анализ на дифрактометре Empyrean PANalitikal в фильтрованном излучении хромового анода $(\lambda=0.2291 \mathrm{~nm})$ с пропорциональным детектором. Рентгенограммы обрабатывались с использованием программы High Score
Plus c базой данных PDF-2. Удельное сопротивление $\rho$ измерялось при температуре $T=20^{\circ} \mathrm{C}$ : в интервале $0-10^{5} \Omega \cdot \mathrm{cm}$ четырехзондовым методом, в области более высоких значений с помощью прибора Megger MIT 1025.

На рис. $1, a, b$ представлены кривые ДСК для исходных образцов с разным содержанием ТУ, а также для образцов, насыщенных пероксидом. Отметим, что, поскольку при изменении температуры эндо- или экзотермические процессы в исследуемых образцах композита в определяющей степени связаны с изменениями состояния матрицы, кривые на рисунках приведены в пересчете на единицу массы этой матрицы, для чего скорректированы (умножены) по ординате на коэффициент $k=1 /(1-C)$, где $C$ - содержание ТУ. Как следует из полученных результатов, процессы изменения состояния матрицы в исследуемом температурном интервале $20-150^{\circ} \mathrm{C}$ являются обратимыми. Обратимость подтверждается характером кривых ДСК при снижении температуры и результатами при повторной регистрации кривых ДСК для тех же образцов. Кроме процессов стеклования имеют место процессы плавления при возрастании температуры и соответственно кристаллизации при ее уменьшении. Два ярко выраженных пика (пики 1 и 2) на кривых для композита, не насыщенного пероксидом, свидетельствуют о полиморфизме кристаллической структуры полимерной матрицы - наличии двух кристаллических фаз: фазы 1 и более высокотемпературной фазы 2. Видно, что доля фазы 2, которая пропорциональна площади соответствующего пика, практически линейно возрастает с содержанием ТУ. Если в образце с содержанием ТУ 5 wt.\% пик, соответствующий фазе 2, практически не наблюдается, то при дальнейшем увеличении содержания ТУ он становится все более заметным. Видно также, что температура плавления этой фазы возрастает с увеличением $C$. Такая ярко выра- 

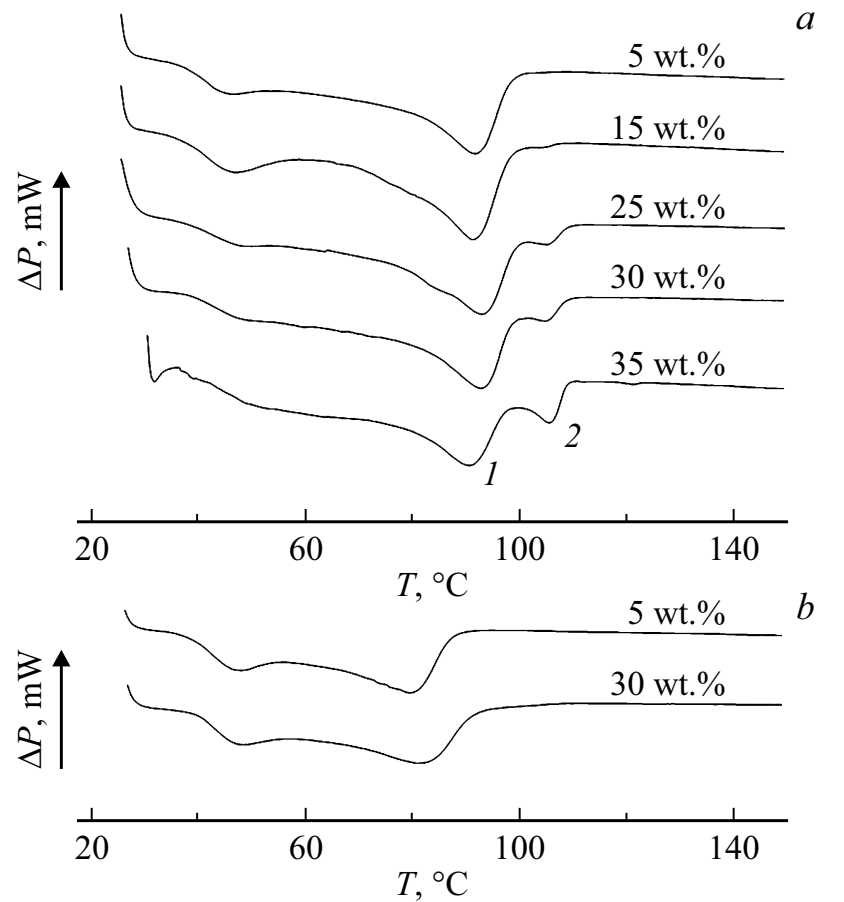

Рис. 1. Кривые ДСК для образцов с различным содержанием ТУ: $a-$ исходных, $b-$ насыщенных пероксидом.

женная зависимость доли полимерной кристаллической фазы 2 от содержания ТУ позволяет сделать вывод о том, что ее формирование инициировано частицами технического углерода или агломератами (цепочками) таких частиц, т. е. последние являются центрами образования кристаллических фрагментов, образуемых макромолекулами матрицы, подобно тому как на углеродных нанотрубках образуется определенная упорядоченная структура (в виде полимерных „нанобусинок“), которая обнаружена в работе [8]. Сложная структура кривых ДСК наблюдалась и в работе [10], где исследовалось влияние ТУ на фазовый состав композита с матрицей из поли(3-гидроксибутирата).

Таким образом, специфика межфазного взаимодействия макромолекул матрицы с частицами ТУ ведет к формированию дополнительной кристаллической фазы с некоторыми особенностями структуры, что предопределяет и более высокое значение температуры ее плавления. Отметим, что наличие этой фазы приводит также к дополнительному влиянию на температурную зависимость удельного сопротивления [11], проявляющемуся в возникновении характерной нерегулярности на соответствующей кривой.

Характер кривых ДСК для образцов композита, насыщенного пероксидом, существенно отличается: они имеют один пик, что свидетельствует о наличии в таких образцах лишь одной кристаллической фазы, причем с температурой плавления, несколько меньшей (примерно на $8^{\circ} \mathrm{C}$ ) соответствующей температуры для доминирующей фазы композита, не насыщенного пероксидом.
Отсутствие второй кристаллической фазы в композите, насыщенном пероксидом, можно объяснить тем, что присутствие пероксида блокирует межфазное взаимодействие макромолекул матрицы с частицами ТУ, а также тем, что сшивка макромолекул, обусловленная пероксидом, подавляет кристаллизацию, инициируемую частицами технического углерода. В таком композите в одной группе макромолекул присутствие пероксида приводит к сшивке, которая может происходить при температурах, начиная с комнатной, в другой, по-видимому, наоборот, пероксид ослабляет связь между макромолекулами и ограничивает их подвижность. Это приводит к образованию менее совершенных полимерных кристаллов и, как следствие, отмеченному выше снижению температуры плавления кристаллической фазы по сравнению с таковой для исходного композита.

Приведенные выше выводы подтверждаются также результатами рентгеноструктурного анализа. На рис. 2 представлены рентгенограммы для исходного образца и образца, насыщенного пероксидом, в которых содержание ТУ составляло $30 \mathrm{wt} . \%$. Видно, что на рентгенограмме композита без пероксида наблюдаются два дифракционных максимума (пики 1 и 2) и „гало“, тогда как на рентгенограмме композита, насыщенного пероксидом, - лишь один максимум (пик 1), „гало“, а также пик с очень малой интенсивностью. Из вида дифракционной картины следует, что структура образца состоит из совокупности молекул, часть которых находится в разупорядоченном, а часть - в упорядоченном (кристаллическом) состоянии. Оценка степени кристалличности $(K)$ по отношению $S_{\text {cryst }} /\left(S_{a m}+S_{\text {cryst }}\right)$, где $S_{a m}$ и $S_{\text {cryst }}$ - площади „гало“ и дифракционных максимумов от „кристаллической“ части соответственно, указывает на явную зависимость $K$ от насыщения образца пероксидом. Значение этого параметра составляет 0.48 для исходного образца и 0.28 для образца, насыщенного пероксидом. Из рис. 1 и 2 видно, что характер рент-

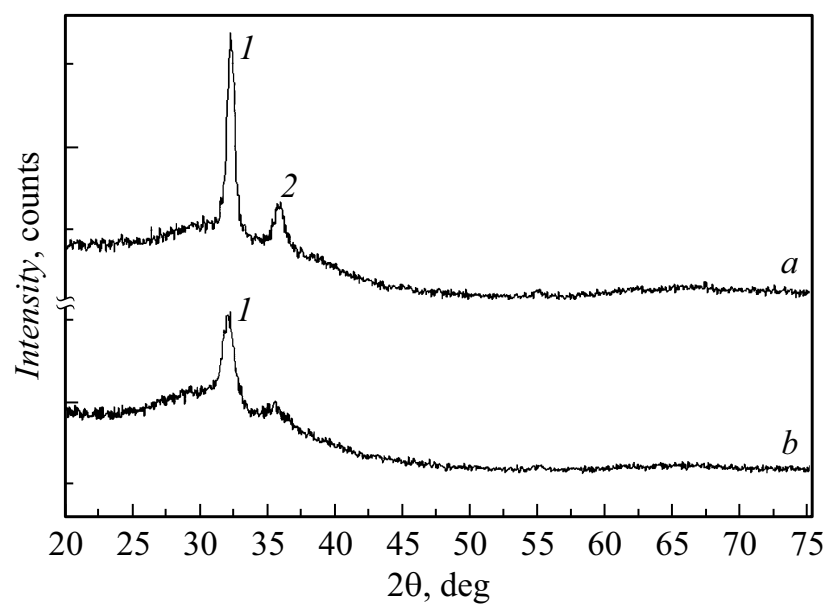

Рис. 2. Рентгенограммы образцов композита с содержанием ТУ, равным 30 wt.\%: $a$ - исходного, $b-$ насыщенного пероксидом. 


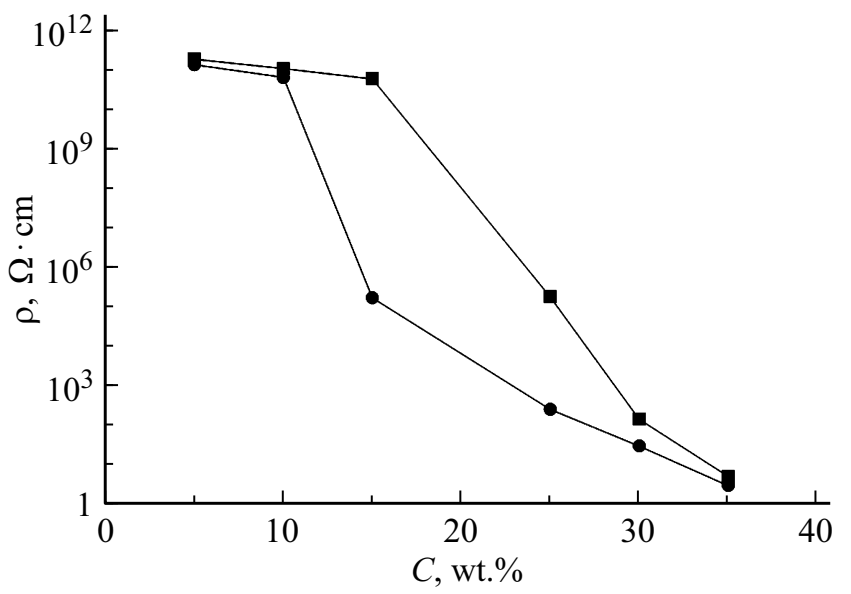

Рис. 3. Зависимости удельного сопротивления композита от содержания ТУ. Кружки - исходные образцы, квадраты образцы, насыщенные пероксидом.

генограмм коррелирует с соответствующими кривыми ДСК и подтверждает вывод о том, что в композите без пероксида имеются две полимерные кристаллические фазы.

Нами также было исследовано влияние насыщения пероксидом на электропроводность композита. Как следует из полученных результатов (рис. 3), величина изменения удельного сопротивления, обусловленная присутствием пероксида, весьма существенным образом зависит от содержания технического углерода. Видно, что наибольший эффект изменения удельного сопротивления, обусловленный присутствием пероксида, проявляется при концентрациях ТУ, соответствующих области перколяции. Это можно объяснить следующим. При малых концентрациях расстояние между частицами ТУ довольно велико и вклад в проводимость, обусловленный прыжковым механизмом и туннелированием, весьма мал. Поэтому наличие или отсутствие пероксида слабо влияет на удельное сопротивление. При концентрациях технического углерода, соответствующих области перколяции, прыжковый механизм и механизм, обусловленный туннелированием, начинают вносить все больший вклад в проводимость. Присутствие же молекул пероксида оказывает блокирующее действие на эти механизмы. С дальнейшим увеличением концентрации ТУ в области перколяции все больший вклад в проводимость начинают вносить цепочки (или пространственная сетка) непосредственно контактирующих между собой частиц технического углерода, на проводящие свойства которых присутствие пероксида оказывает существенно меньшее влияние. При больших $(C \geqslant 30 \mathrm{wt} . \%)$ концентрациях ТУ этот вклад в проводимость становится доминирующим. В этом случае присутствие пероксида может нарушать непосредственный контакт между некоторыми частицами, приводя тем самым к возрастанию $\rho$, но уже в значительно меньшей степени, чем при концентрациях, соответствующих области перколяции.
Таким образом, в работе обнаружено существование дополнительной, более высокотемпературной кристаллической фазы в полимерном композите, не насыщенном пероксидом. Установлено, что относительная доля этой фазы прямо связана с содержанием технического углерода. Эта зависимость, а также данные рентгеноструктурного анализа позволяют сделать вывод о том, что частицы технического углерода способствуют зародышеобразованию дополнительной кристаллической фазы в матрице этиленвинилацетата. Также установлено, что насыщение пероксидом влияет на полиморфизм кристаллической структуры композита и его электропроводность. В наибольшей степени влияние пероксида на электропроводность наблюдается при концентрациях технического углерода, соответствующих области перколяции. Полученные результаты помимо научного представляют практический интерес и могут быть использованы при разработке новых электропроводящих композитов на основе этиленвинилацетата.

\section{Финансирование работы}

Работа выполнена при финансовой поддержке Российского фонда фундаментальных исследований и Правительства Республики Мордовия в рамках научного проекта № 18-48-130015 p_a.

\section{Конфликт интересов}

Авторы заявляют, что у них нет конфликта интересов.

\section{Список литературы}

[1] Блайт Э.Р., Блур Д. Электрические свойства полимеров. М.: Физматлит, 2008. 376 с.

[2] Борукаев Т.А., Гаев Д.С. // Прикладная физика. 2017. № 5. C. $76-81$.

[3] Mather P.J., Thomas K.M. // J. Mater. Sci. 1997. V. 32. N 2. P. 401-407.

[4] Марков В.А., Гущин В.А., Марков А.В. // Пластические массы. 2019. В. 1-2. С. 44-47.

[5] Степашкина А.С., Цобкалло Е.С., Москалюк О.А., Алешин А.Н. // Письма в ЖТФ. 2015. Т. 41. В. 2. С. 7-14.

[6] Заикин А.Е., Жаринова Е.А., Бикмуллин Р.С. // Высокомолекуляр. соединения А. 2007. Т. 49. № 3. С. 499-509.

[7] Rahaman M., Chaki T.K., Khastgir D. // J. Mater. Sci. 2013. V. 48. N 21. P. 7466-7475.

[8] Гусев К.В., Ванин А.И., Соловьев В.Г., Gerbreders V., Ogurcovs A. // Письма в ЖТФ. 2020. Т. 46. В. 11. С. 8 10.

[9] Aneli J., Zaikov G., Mukbaniani O. // Chem. Chem. Technol. 2011. V. 5. N 1. P. 75-87.

[10] Wellen R.M.R., Canedo E.L., Rabello M.S. // J. Mater. Res. 2015. V. 21. N 13. P. 3211-3226.

[11] Зюзин А.М., Карпеев А.А., Янцен Н.В. // Письма в ЖТФ. 2020. T. 46. B. 12 . C. 3-5. 